\title{
Boredom vs. cognitive reappraisal in the development of cooperative strategy ${ }^{1}$
}

\author{
MARC PILISUK, PAUL SKOLNICK, KENNETH THOMAS \\ Purdue University \\ and \\ REUBEN CHAPMAN \\ University of Michigan
}

When two players face each other in a typical Prisoner's Dilemma game, there are no rational calculations which can determine whether to cooperate or to defect. Yet, after repeated plays, the two players come to play increasingly like each otherboth cooperating (Doves) or both defecting (Hawks). Also, after very lengthy sequences, the number of pairs in which both members are cooperating exclusively tends to increase (Rapoport, 1965). Such changes in behavior may reflect restlessness, as suggested by Lave (1965), or they may reflect increasingly deeper cognitive depictions of the relationships between the two players. An article which propounded the latter theory (Pilisuk, Potter, Rapoport, and Winter, 1965) was based upon findings in a multi-choice Prisoner's Dilemma game. The purpose of this article is to review those findings and to use the methods of that study in a direct test of whether it is boredom or need for activity on the one hand,

\footnotetext{
${ }^{1}$ Work on this study was conducted under Grants G99 and G999 from the National Science Foundation. Portions of this paper were presented at the meeting of the Midwestern Psychological Association in Chicago in May 1966.
}

or cognitive reappraisal on the other, that might be the reason for eventual shifts in strategy.

In order to create a sensitive measure of cooperation and defection, Pilisuk and Rapoport (1964b) developed an extended version of the Prisoner's Dilemma. The customary $2 \times 2$ payoff matrix was "stretched" to a $21 \times 21$ matrix which preserved the mixed motivation of the original game and yet allowed twenty degrees of cooperation or defection.

The game is played in an "abstract" form in which each player is given 20 poker chips, white on one face, blue on the other. Both players begin with 20 white chips exposed and indicate their degree of cooperation by turning some number of these to their blue sides. The payoffs accruing to the players reflect the mutuality of their performance in a manner exactly analogous to the two-choice condition. A reduced form of the $21 \times 21$ matrix is shown in Figure 1 .

From this it is clear that the minimax solution, as in two-choice Prisoner's Dilemma games, is not to cooperate, not to turn a single token from white to blue. The subject who leaves all tokens white side up is better off regardless of the degree of co- 
Other person's missiles at end of experiment

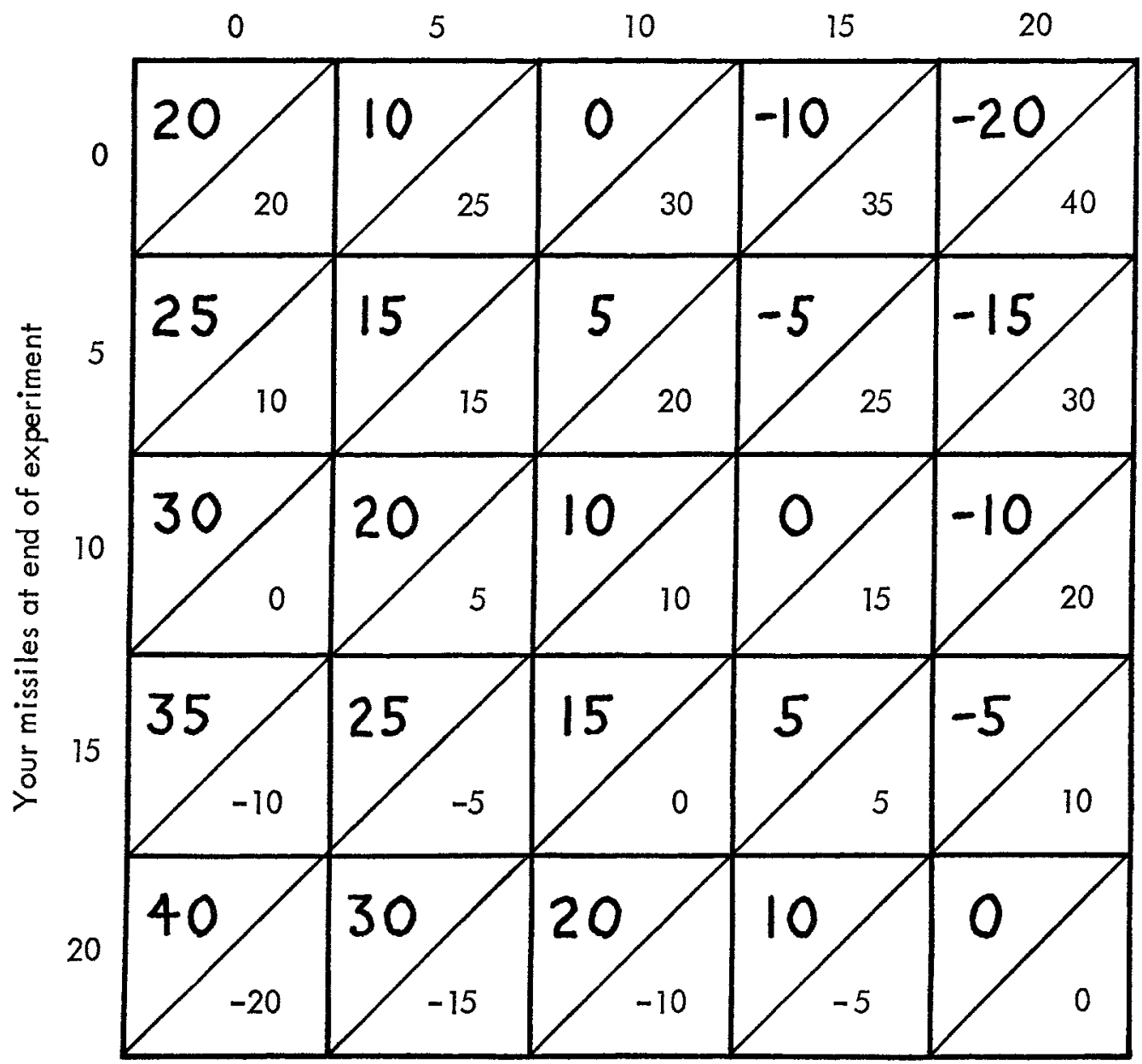

Fig. 1. Reduced form of payoff matrix shown to players. The actual matrix showed all values from 0 to 20 . The first figure in each box represents one's own payoff; the second figure, the payoff for the other player. Missiles are equivalent to white face tokens.

operation of the partner. The dilemma is identical to the two-choice game. There is room, however, to indicate a measure of cooperation without exposing oneself to maximal loss.

The term "abstract" used to describe the above game is in contrast to the "simulated" condition. In the latter condition the tokens bear a picture of a missile on each white surface and of a factory on each blue surface. The game then becomes, in capsule form, an armament-disarmament dilemma. Let us briefly indicate that gross cooperation rates were not affected by the simulation, not even when looked at in conjunction with several personality and attitude variables (Pilisuk, Potter, Rapoport, and Winter, 1965). 


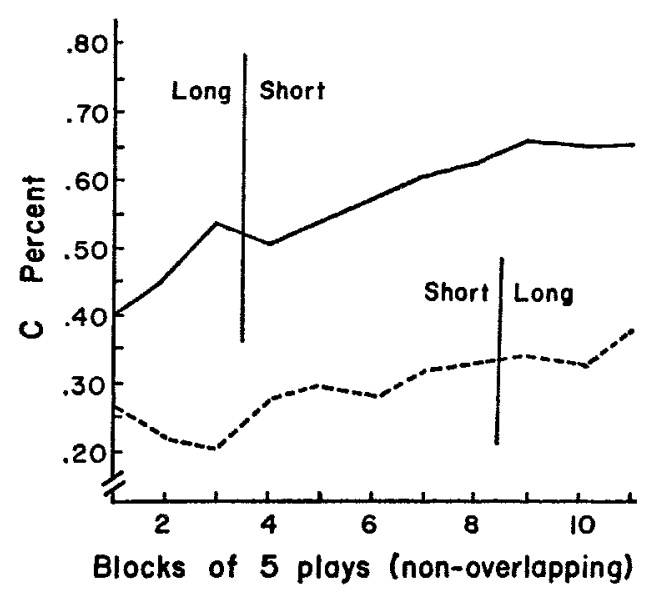

Fic. 2. The time courses of the abstract game, showing percent cooperation (C). Broken line: short version was played first ( 40 plays). Solid line: long version was played first ( 15 plays).

It is important to note parenthetically that, even in simulated conditions, the experiment rigidly controls the neutrality of instructional sets which might be conducive to either individualistic or group orientation, and it gives no instruction as to the subject's purpose other than what the subject may himself infer from the matrix or from the connotations of the labels.

Another variation of the extended Prisoner's Dilemma game has proven more relevant to the rate of cooperation and provides the point of departure for the present study. In the first of two types, called the short game, a single decision is made by each player, simultaneously and in isolation, as to the number of his twenty poker chips which he would like to convert from white to blue, from missiles to factories. After each play, the experimenter informs each player of the number of missiles the other has displayed. From this he may refer to his payoff matrix and calculate his earnings.

The long game slow's the process by per-

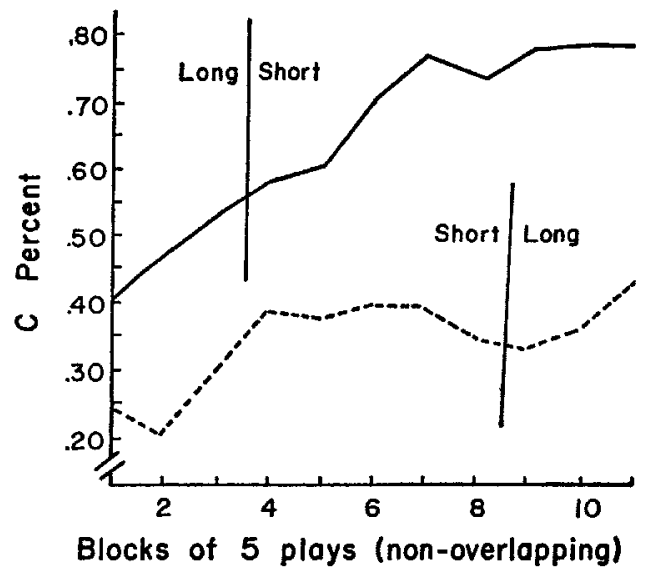

FIG. 3. The time courses of the simulated game. Broken line: short version was played first (40 plays). Solid line: long version was played first ( 15 plays).

mitting conversion of no more than two chips per move. Subjects are given twenty moves per play of the game; but the results of moves 1-19 are not made known to the other player, nor do they affect the final payoffs, which are determined solely by the state of the two players on the twentieth move. Hence the long game and the short game are logically isomorphic.

In this earlier study there were two experimental conditions. In the first, players began the experiment with 15 protracteddecision (long) games (which set the pattern for subsequent behavior) and then played 40 immediate-decision (short) games. In the other experimental condition, the 40 immediate-decision games were played first (again setting the pattern for subsequent behavior).

Among the findings was the tendency for graduated decisions (or protracted decision time) to result in a greater amount of cooperative behavior, i.e., mutual disarmament in this case. Figure 2 shows the aver- 
age percent cooperation (number of factories divided by 20) of the subjects in the two conditions with the abstract game. The data are graphed according to five game blocks. Figure 3 shows an identical comparison for the groups who played the simulated game (Pilisuk and Rapoport, 1964a).

Logically, the task was the same in all conditions. Yet subjects who began with the graduated-decision games tended to show greater cooperation than those who started with single-decision games. The graduated decisions produced more pairs of Doves, i.e., pairs mutually cooperating to a high criterion level during the last five games of a 55-game sequence (Pilisuk et al., 1965).

The interpretation offered for this finding was that the achievement of mutual cooperation most likely required a series of cognitive reappraisals of the subjects' initial perspectives. The theory characterizes the development of mutual trust as a phased process. In the first phase the game is viewed as if it were a game against nature which permits no control or influence over the other's behavior. In the second phase a realization takes place that behaviors (one's own or the other player's) can communicate intentions and may be purposefully used with that in mind. Finally, another reappraisal brings about the awareness of a common fate in which the two players see themselves as a social unit and need compete no longer. This three-phase theory involving cognitive recasting was consistent with the findings that pairs mutually tolerant of ambiguity tended to progress through the stages most completely. Analysis of the experiences of early play and the remarks of the players seemed to coincide with the stages suggested. It seemed not unlikely, then, that conditions of protracted decision would allow more time to reappraise and therefore to promote the evolution of stages toward trust.

It was necessary, however, to consider the possibility that a simpler, more mechanical factor might be operating to produce these results. In all conditions, whether protracted-decision or immediate-decision, the game was structured as a peace race. Players started with the highest permissible level of armament and made their moves by either disarming or standing pat. Perhaps, for reasons of boredom or need for activity, it was easier to stand pat and remain armed through the single move game than to bypass twenty consecutive turns to take more gradual steps. The following experiment was designed to test this alternative explanation. The exact design of the earlier study was repeated with only a single modification: the players start from a fully disarmed condition, and the need for movement or activity now favors a lower rather than a higher rate of cooperation or disarmament.

\section{Method of the Current Experiment}

One hundred twenty-eight subjects participated in the earlier "peace race" version of this extended Prisoner's Dilemma. Forty subjects were used in the new "arms race" version. All subjects were male college students. Volunteers were paid for their participation. (Actual monetary rewards were dependent upon game winnings.)

All participated in pairs, and acquaintances were not paired. Subjects were seated at a table with a partition separating each player from the others (none of the subjects could see each other). Half the subjects were run in the long-first condition described above (15 trials of the long game followed by 40 trials of the short game), and the other half were run in the shortfirst condition ( 40 trials of the short game 
TABLE 1

Expernemental Design

\begin{tabular}{|c|c|c|}
\hline \multicolumn{2}{|c|}{ PEACE RACE } & \multirow{2}{*}{$\frac{\text { ARMS RACE }}{\text { Simulated }}$} \\
\hline Abstract & Simulated & \\
\hline Long games ${ }^{e}$ first & Long games first & Long games first \\
\hline Abstract & Simulated & Simulated \\
\hline Short games ${ }^{d}$ first & Short games first & Short games first \\
\hline
\end{tabular}

a Cooperation requires activity.

b Noncooperation requires activity.

c Twenty opportunities to move during a game.

d One opportunity to move per game.

followed by 15 trials of the long game). The experimental design, incorporating both the previous experiments and the current one, is shown in Table 1.

\section{Results and Discussion}

The data deal with characteristics of three types of pairs. The pairs were classified into discrete categories in accordance with the performance of both players during the last five games of the experimental session containing 55 games. The pair labels are Dove (cooperators), Hawk (noncooperators), and Mugwump (intermediate). A pair was labeled Dove if (1) both players had 15 or more of their chips showing factories at the end of each of the last five games and (2) neither player had fewer than 17 factories showing on an average over these same trials. The Hawk criteria are completely symmetrical. A Hawk pair was so designated where (1) neither player had more than five chips showing factories during the last five games and (2) neither player had turned more than three factories per trial during these same games. The third and intermediate group, Mugwumps, contains all the remaining pairs which failed to meet the conditions for classification as either Dove or Hawk. These groupings, while arbitrary, provide for stringent differentiation between the cooperators (Doves) and the noncooperators (Hawks). The probability that two players making random choices will fall into one of these two groups is less than $10^{-5}$. The criteria are reproduced exactly from the earlier study (Pilisuk, Potter, Rapoport, and Winter, 1965).

In the original "peace race," since cooperation required activity, it seemed possible to explain the greater cooperation in the prolonged, graduated decision game, as compared with performance in the single decision game, by boredom or need for activity-i.e., the player could not bypass 20 opportunities to do something (in this case, disarm). However, in the arms race, it was arming which required the activity; therefore, we would expect less cooperation in the long game, first condition, if the explanation involving boredom or need for activity is to hold.

The results clearly do not support this position. In fact, the trend is in the opposite direction. Figure 4 shows the average percent cooperation (graphed according to fivegame blocks) of subjects in the two conditions of the current experiment. As in the prior experiment, there is more cooperation when the prolonged-decision game is played first, even though it is now noncooperation that requires activity. The Mann-Whitney $\mathrm{U}$ test, performed on average cooperation per pair over the pairs in both conditions, 


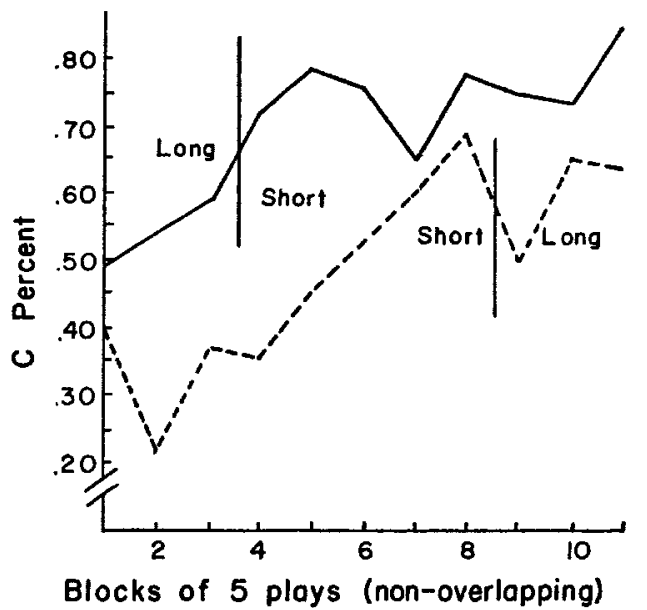

Fig. 4. The time courses of the reverseddirection (arms race) game. Broken line: short version was played first ( 40 plays). Solid line: long version was played first ( 15 plays).

yields a $U$ of 25 which is significant at the .05 percent level. Furthermore, there were eight pairs of Doves ( 80 percent) among the subjects in the long-first condition, and only five pairs of Doves (50 percent) in the short-first condition. (Tables 2 and 3 show the distribution of Doves, Hawks, and Mugwumps for all conditions.) Over all the conditions the trend emerges that the long-first condition is more conducive to producing mutually cooperative "Doves" than the short-first condition.

Clearly, a need for activity was not responsible for the increased cooperation shown by subjects in the long-first conditions. In fact, comparing Figures 3 and 4 , we can see that the difference in percent cooperation between long-first and shortfirst conditions is approximately the same whether the subjects go from missiles to factories or from factories to missiles. This difference is approximately four factories per player per play, or an average of 20 percent higher cooperation for the protracted-decision game.

The two present conditions, like the four described previously, show the same trend toward increased cooperation over time. There was a small (though not statistically significant) difference between the rates of cooperation when the direction was shifted from peace race to arms race. The longfirst and the short-first condition of the arms race each produced an average of two more factories per player per game than the comparable conditions in the peace race.

TABLE 2

Number of Doves, Hawks, and Mugwumps for the Four Simulated Conditions

\begin{tabular}{|c|c|c|c|c|}
\hline Conditions & Doves & Hawks & Mugwumps & Total \\
\hline \multicolumn{5}{|c|}{ Peace race (missiles to factories): } \\
\hline Long-first conditions & $\begin{array}{c}8 \\
(50 \%)\end{array}$ & $\stackrel{2}{(12.5 \%)}$ & $\begin{array}{c}6 \\
(37.5 \%)\end{array}$ & 16 \\
\hline \multirow[t]{2}{*}{ Short-first conditions } & $\begin{array}{c}5 \\
(31.2 \%)\end{array}$ & $\begin{array}{c}6 \\
(37.5 \%)\end{array}$ & $\begin{array}{c}5 \\
(31.2 \%)\end{array}$ & 16 \\
\hline & & & & 32 \\
\hline \multicolumn{5}{|c|}{ Arms race (factories to missiles): ${ }^{\mathrm{a}}$} \\
\hline Long-first conditions & $\begin{array}{c}8 \\
(80 \%)\end{array}$ & $\stackrel{1}{(10 \%)}$ & $\begin{array}{c}1 \\
(10 \%)\end{array}$ & 10 \\
\hline \multirow[t]{2}{*}{ Short-first conditions } & $\begin{array}{c}5 \\
(50 \%)\end{array}$ & $\begin{array}{c}1 \\
(10 \%)\end{array}$ & $\begin{array}{c}4 \\
(40 \%)\end{array}$ & 10 \\
\hline & & & & $\overline{20}$ \\
\hline
\end{tabular}

a Chi-square not significant. Comparisons between peace race and arms race conditions also yield nonsignificant chi-square. 
TABLE 3

Number of Doves, Hawks, and Mugwumps for Agstract Condttons Alone and for Alt LONG-FIRST AND SHORT-FIRst Conditions CombINED

\begin{tabular}{|c|c|c|c|c|}
\hline Conditions & Doves & Hawks & Mugwumps & Total \\
\hline \multicolumn{5}{|c|}{$\begin{array}{l}\text { Abstract game (with cooperation } \\
\text { requiring activity): }\end{array}$} \\
\hline Long-first conditions & $\stackrel{11}{(68.8 \%)}$ & $\begin{array}{c}4 \\
(25 \%)\end{array}$ & $\begin{array}{c}1 \\
(6.2 \%)\end{array}$ & 16 \\
\hline Short-first conditions & $\begin{array}{c}2 \\
(12.5 \%)\end{array}$ & $\begin{array}{c}5 \\
(31.2 \%)\end{array}$ & $\begin{array}{c}9 \\
(56.2 \%)\end{array}$ & 16 \\
\hline$x^{2}=12.141, p<.01$ & & & & 32 \\
\hline \multicolumn{5}{|l|}{$\begin{array}{l}\text { Peace race, arms race, and } \\
\text { abstract game combined: }\end{array}$} \\
\hline Long-first conditions & $\stackrel{27}{(64.3 \%)}$ & $\begin{array}{c}7 \\
(16.7 \%)\end{array}$ & $\begin{array}{c}8 \\
(19.05 \%)\end{array}$ & 42 \\
\hline Short-first conditions & $\begin{array}{c}12 \\
(28.6 \%)\end{array}$ & $\begin{array}{c}12 \\
(28.6 \%)\end{array}$ & $\begin{array}{c}18 \\
(42.9 \%)\end{array}$ & 42 \\
\hline$\chi^{2}=10.932, \mathrm{p}<.01$ & & & & 84 \\
\hline
\end{tabular}

After stating that there may well be nothing but chance operating in the variation, there is still some room for the luxury of speculation about what factors might be operating here, at least for some players. One possibility is that a player whose partner (or opponent) begins with 20 factories feels that there is a greater chance that his partmer will retain most of them, whereas a player whose partner begins with 20 missiles imagines it less likely that his partner will convert most of them. Still another possibility is that subjects who begin each game at the upper left-hand corner of the payoff matrix (with all factories and a payoff of 20) take more cognizance of this alternative as a possible end-state.

The only notable finding of this study is one which bears upon the question of whether it is boredom or cognitive reappraisal which mediates behavioral change in the Prisoner's Dilemma game. The influence of boredom alone or of a need for activity as the cause for eventual shift to cooperative strategy is discredited by these data. The theory remains tenable that evo- lution of trust goes through phases brought on by a time-dependent cognitive reappraisal of the relationship.

\section{REFERENCES}

LAvE, L. B. "Factors Affecting Cooperation in the Prisoner's Dilemma," Behavioral Science, 10 (1965), 26-38.

Pilisuk, M., and A. Rapopont. "A Non-Zero Sum Game Model of Some Disarmament Problems." Peace Research Society: Papers 1, Chicago Conference, 1963 (1964a).

- - "Stepwise Disarmament and Sudden Destruction in a Two-Person Game: A Research Tool," Journal of Conflict Resolution, 8, 1 (March 1964b), 36-49.

Plisuk, M., P. Potter, A. Rapoport, and J. Winter. "War Hawks and Peace Doves: Alternate Resolutions to Experimental Conflicts," Journal of Conflict Resolution, 9, 4 (Dec. 1965), 491-508.

Rapoport, A., and A. Chammay. The Prisoner's Dilemma. Ann Arbor: University of Michigan Press, 1965.

—, and Carol Orwant. "Experimental Games: A Review," Behavioral Science, 7 (1962), 1-37.

Siegal, S., and L. Fouraker. Bargaining and Group Decision Making. New York: McGraw-Hill, 1960. 